\title{
TAHSP:-
}

The Internet Joưnal of Allied Health Sciences and Practice

A Peer Reviewed Publication of the College of Health Care Sciences at Nova Southeastern University

Dedicated to allied health professional practice and education

http://ijahsp.nova.edu Vol. 12 No. 4 ISSN 1540-580X

\section{Physiotherapy Management of Post-Operative Breast Cancer Patients: A Qualitative Study}

\author{
Dragana Ceprnja, B.Phyty ${ }^{1}$ \\ Katherine Maka, B.AppSciPhyty2
}

1. Health Professional Educator, Physiotherapy Department, Westmead Hospital, Sydney, New South Wales

2. Senior Physiotherapist, Physiotherapy Department, Westmead Hospital, Sydney, New South Wales

Australia

CITATION: Ceprnja D, Maka K. Physiotherapy Management of Post-Operative Breast Cancer Patients: A Qualitative Study. The Internet Journal of Allied Health Sciences and Practice. Oct 2014. Volume 12 Number 4.

\section{ABSTRACT}

Purpose: Post-operative breast cancer patients receive physiotherapy to improve range of motion, reduce pain, and increase strength. The aim of this study was to provide qualitative information about which techniques are utilised by physiotherapists in the management of post-operative breast cancer patients in a hospital physiotherapy outpatient department setting in Western Sydney, Australia. Method: Common interventions were listed on a survey and physiotherapists were asked to select which treatment interventions they used and the frequency of use. Results: A total of 20 surveys were completed out of 25 disseminated. The most commonly used intervention was stretches with $100 \%$ of respondents using stretches frequently. This was followed by range of motion exercises with $95 \%$ using this intervention frequently. General arm care advice and postural education were frequently utilised by $80 \%$ of respondents. Conclusions: The most common physiotherapy interventions used in the management of post-operative breast cancer patients were shoulder stretches, glenohumeral joint range of motion exercises, general arm care advice, and postural education.

\section{INTRODUCTION}

Post-operative breast cancer patients are commonly referred to physiotherapy for treatment of reduced shoulder complex function and associated pain. It is known that post-operatively, patients can lack shoulder range of motion, experience pain, and have reduced shoulder strength. ${ }^{1}$ Evidence supports that physiotherapy can improve shoulder range of motion. ${ }^{2}$ There is growing evidence as to the benefits of strengthening or resistive exercises, including improved strength, improved quality of life, and reduced incidence of lymphoedema. ${ }^{3-8}$ Exercise is an important component of the cancer rehabilitation continuum. ${ }^{9-12}$

Manual therapy, mostly using soft tissue techniques, combined with education and advice has been shown to be beneficial in a single case study of physiotherapy treatment of a post-operative breast cancer patient. ${ }^{13}$ Physiotherapy interventions are also needed to address issues related to lymphoedema, fatigue, pain, and chemotherapy-induced peripheral neuropathy (CIPN).

The aim of this study was to provide qualitative information about which techniques are utilised by physiotherapists in the management of post-operative breast cancer patients in a hospital physiotherapy outpatient department setting in Western Sydney, Australia.

\section{METHODS}

A survey form (see Appendix 1) was developed after review of relevant literature by two senior physiotherapists with over 20 years combined experience in the management of post-operative breast cancer patients. This form was then forwarded to 3 
other senior physiotherapists working in the field of breast cancer for peer review and comment. The survey was forwarded to a cohort of 25 physiotherapists who are involved in the outpatient care of patients post breast cancer surgery. The selection process was a sample of convenience as these physiotherapists all worked in the physiotherapy outpatient departments of public hospitals within the local health district of Western Sydney, Australia. Physiotherapists were asked to select if they used the listed interventions frequently, occasionally, or never. A further section was labelled "other" where the physiotherapist could list other interventions they may utilise that were not included in the survey.

\section{RESULTS}

Twenty completed surveys were returned, giving a response rate of $80 \%$. The respondents had an average of 9.5 years experience (range 6 months to 31 years) working with post-operative breast cancer patients in a hospital physiotherapy outpatient department setting.

The most used intervention was shoulder muscle stretches with $100 \%$ of respondents using stretches frequently. Stretches could be active or passive. This was followed by glenohumeral joint range of motion exercises with $95 \%$ using this intervention frequently. General arm care advice and postural education were utilised by $80 \%$ of respondents frequently. Soft tissue techniques were employed frequently by $60 \%$ of respondents and occasionally by $30 \%$ of respondents. Strengthening exercises were administered frequently by $45 \%$ of respondents and occasionally by $50 \%$ of respondents. No other interventions were listed by respondents in the completed surveys.

Table 1. Interventions Utilised By Physiotherapists

\begin{tabular}{|l|l|l|l|}
\hline Intervention & Frequently (\%) & Occasionally (\%) & Never (\%) \\
\hline Soft tissue techniques & $12(60 \%)$ & $6(30 \%)$ & $2(10 \%)$ \\
\hline Shoulder stretches & $20(100 \%)$ & - & - \\
\hline $\begin{array}{l}\text { G/H Joint range of motion } \\
\text { exercises }\end{array}$ & $19(95 \%)$ & $1(5 \%)$ & - \\
\hline Strengthening exercises & $9(45 \%)$ & $10(50 \%)$ & $1(5 \%)$ \\
\hline General arm care advice & $16(80 \%)$ & $3(15 \%)$ & $1(5 \%)$ \\
\hline Postural education & $16(80 \%)$ & $3(15 \%)$ & $1(5 \%)$ \\
\hline General fitness & $3(15 \%)$ & $12(60 \%)$ & $5(25 \%)$ \\
\hline Exercise group programs & $1(5 \%)$ & $6(30 \%)$ & $13(65 \%)$ \\
\hline Hydrotherapy & $2(10 \%)$ & $7(35 \%)$ & $11(55 \%)$ \\
\hline Passive mobilisations & $2(10 \%)$ & $11(55 \%)$ & $7(35 \%)$ \\
\hline $\begin{array}{l}\text { Electrophysical agent } \\
\text { modalities }\end{array}$ & $1(5 \%)$ & $4(20 \%)$ & $15(75 \%)$ \\
\hline Neural tension techniques & $8(40 \%)$ & $7(35 \%)$ & $5(25 \%)$ \\
\hline Taping & $1(5 \%)$ & $11(55 \%)$ & $8(40 \%)$ \\
\hline Other & - & - & - \\
\hline
\end{tabular}

Table 1 provides the results for each intervention used frequently, occasionally, and never.

\section{DISCUSSION}

The results that the most commonly used techniques were shoulder muscle stretches and glenohumeral joint range of motion exercises were not surprising given that post-operative breast cancer patients frequently experience reduced shoulder range of motion. ${ }^{1}$ General arm care advice was also used by three-quarters of respondents frequently because physiotherapists are in a unique position to provide this education given their knowledge and skill in rehabilitation of upper limb function post-operatively. Patients often present to physiotherapy with many questions specific to their upper limb function which have not been addressed by other health professionals. ${ }^{6}$ For example, physiotherapists provide information about return to activity and advice on activity modifications necessary at different stages of the post-operative recovery. The frequent use of postural education is important because many of these patients develop altered shoulder girdle alignment post-operatively as a result of pain, the presence of drain tubes and surgical incisions, inconsistent advice, and body image stigma. ${ }^{1}$ The provision of such education may also reflect the holistic approach favoured by many physiotherapists in providing advice and exercises to improve general wellbeing in their patients, including those post breast cancer surgery. ${ }^{2}$

The results reveal that half the respondents use strengthening exercises occasionally. Given the well known post-operative sequelae of reduced strength and the strong evidence that exists in supporting the positive benefits of strengthening exercises, it could be expected that physiotherapists would include strengthening exercises more frequently. 5,8 
Similarly, general fitness was used occasionally by sixty percent of respondents. Reduced physical fitness is a common complaint of post-operative breast cancer patients, particularly those patients undergoing adjuvant treatment including chemotherapy and radiation therapy. Recent studies have shown that exercise, even of brief duration, improves the physical fitness of women breast cancer survivors.,14 In light of such evidence, the results do suggest that general fitness may not be utilised as frequently as expected.

A large proportion of respondents reported never using physical exercise group programs. This may reflect the lack of such programs offered in the local hospital community in Western Sydney, Australia.

A limitation of this study is that the physiotherapists surveyed were a convenience sample of physiotherapists working in public hospitals in Western Sydney, Australia. A larger sample of physiotherapists, including those in other regional or rural areas and those working in differing primary work settings, such as community and private practice, would need to be included in future studies to increase the generalizability of results. However, post-operative breast cancer patients receiving physiotherapy are likely to have similar impairments, so we would expect the physiotherapy management to be consistent. It is of note that physiotherapists working in the public hospitals of our health district do not provide lymphoedema management; hence, lymphoedema treatment interventions were not included in this study. Our study looked specifically at physiotherapy treatment interventions for post-operative breast cancer patients, but we acknowledge that there are non-surgical options for breast cancer treatment which may potentially require similar physiotherapy interventions.

\section{CONCLUSION}

Based on our results, the most common physiotherapy interventions used in the management of post-operative breast cancer patients in an outpatient hospital setting were shoulder muscle stretches, glenohumeral joint range of motion exercises, general arm care advice, and postural education.

\section{REFERENCES}

1. Ebaugh D, Spinelli B, Schmitz KH. Shoulder impairments and their association with symptomatic rotator cuff disease in breast cancer survivors. Medical Hypotheses. 2011;77(4):481-7. doi: 10.1016/j.mehy.2011.06.015. Epub 2011 Jul 18. [PMID 21764521]

2. Kilbreath SL, Refshauge KM, Beith JM, Ward LC, Lee M, Simpson JM, Hansen R. Upper limb progressive resistance training and stretching exercises following surgery for early breast cancer: a randomized controlled trial. Breast Cancer Research Treatment. 2012 Jun;133(2)667-76. DOI 10.1007/s10549-012-1964-1. [PMID 22286332]

3. Herrero F, San Juan AF, Fleck SJ, Blamer J, Perez M, Canete S, Earnest CP, Foster C, Lucia A. Combined aerobic and resistance training in breast cancer survivors: A randomized controlled pilot trial. International Journal of Sports Medicine. 2006;27(7):573-80. [PMID 16802254]

4. McNeely ML, Campbell K, Opsina M, Rowe BH, Dabbs K, Klassen TP, Mackey J, Courneya K. Exercise interventions for upper-limb dysfunction due to breast cancer treatment (Review). The Cochrane Library. 2006;16(6):CD005211.[PMID 20556760]

5. Milne HM, Wallman KE, Gordon S, Courneya KS. Effects of a combined aerobic and resistance exercise program in breast survivors: a randomized controlled trial. Breast Cancer Research Treatment. 2008;108(2):279-88. [PMID 17530428]

6. Lee TS, Kilbreath SL, Sullivan G, Refshauge KM, Beith JM. Patient perceptions of arm care and exercise advice after breast cancer surgery. Oncology Nursing Forum. 2010;37(1):85-91. [PMID 20044343]

7. Oliveira MM, Souza GA, Miranda Mde S, Okubo MA, Amaral MT, Silva MP, Gurgel MS. Upper limb exercises during radiotherapy for breast cancer and quality of life. Rev Bras Ginecol Obstet. 2010;32(3):133-8. [PMID 20512260]

8. Kim do S, Sim YJ, Jeong HJ, Kim GC. Effect of active resistive exercise on breast cancer-related lymphedema: a randomized controlled trial. Archives Physical Medicine Rehabilitation. 2010;91(12):1844-8. [PMID 21112424]

9. Hsieh CC, Sprod LK, Hydock DS, Carter SD, Hayward R, Scneider CM. Effects of a supervised exercise intervention on recovery from treatment regimens in breast cancer survivors. Oncology Nursing Forum. 2008;35(6):909-15. [PMID 18980921]

10. Jones LW, Douglas PS, Eves ND, Marcom PK, Kraus WE, Herndon JE, Inman BA, Allen JD, Peppercorn J. Rationale and design of the Exercise Intensity Trial (EXCITE): A randomized trial comparing the effects of moderate versus moderate to high-intensity aerobic training in women with operable breast cancer. BMC Cancer. 2010;10:531. DOI 10.1186/1471-240710-531. [PMID 20925920]

11. Penttinen HM, Saarto T, Kellokumpu-Lehtinen $P$, Blomqvist $C$, Huovinen R, Kautiainen $H$, Jarvenpaa S, Nikander R, Idman I, Luoto R, Siavanen H, Utriainen M, Vehmanen L, Jaaskelainen AS, Elme A, Ruohola J, Luoma M, Hakamies-Blomqvist L. Quality of life and physical performance and activity of breast cancer patients after adjuvant treatments. Psychooncolgy. 2011;20(11):1211-20. \{PMID 20878646\} 
12. Sprod LK, Hsieh CC, Hayward R, Schneider CM. Three versus six months of exercise training in breast cancer survivors. Breast Cancer Research Treatment. 2010;121(2):413-9. [PMID 20443054]

13. Fourie WJ, Robb KA. Physiotherapy management of axillary web syndrome following breast cancer treatment: discussing the use of soft tissue techniques. Physiotherapy. 2009;95(4):314-20. [PMID 19892098]

14. Mehnert A, Veers S, Howaldt D, Braumann KM, Koch U, Schulz KH. Effects of a physical exercise rehabilitation group program on anxiety, depression, body image, and health-related quality of life among breast cancer patients. Onkologie. 2011;34(5):248-53. [PMID 21577030]

\section{ACKNOWLEDGEMENTS:}

We thank the physiotherapists involved in the development of the survey and those who gave their time to complete the surveys.

\section{KEY WORDS}

Breast Cancer, Oncology, Physiotherapy, Physical Therapy, Interventions. 


\section{APPENDIX A}

Survey of physiotherapy treatment techniques used in the post-operative management of breast cancer patients How long have you worked with post-operative breast cancer patients?

months or

years

Please indicate how often you would use the following interventions if your management of post-operative breast cancer patients:

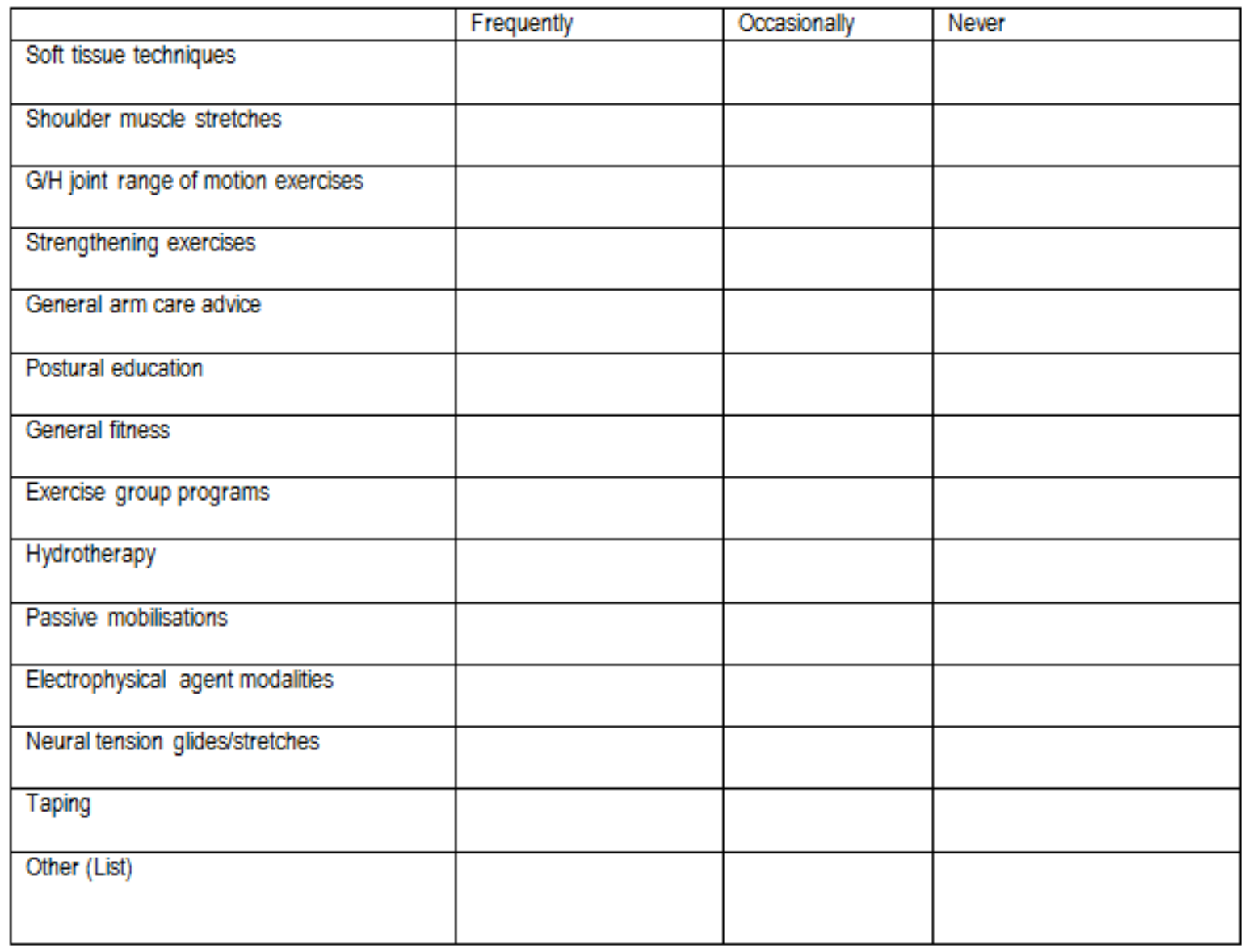

